\title{
EDITORIAL
}

\section{Winter Issue, 2017}

DOI:https://doi.org/10.5770/cgj.20.324

In our final issue for 2017 we present a wide variety of articles, encompassing both original research and subjective commentaries on the life experiences of being a geriatrician. Byszewski et al. ${ }^{(1)}$ examine the impact of a multi-media module on health professionals' level of comfort in discussing cessation of driving. Loftus and Wiesenfeld ${ }^{(2)}$ undertook a baseline quality assurance chart audit to confirm both underrecognition and poor adherence to best practices in delirium management. Dr. Colin Powell ${ }^{(3)}$ describes some of the personal and professional lessons he learned on his journey from a retired geriatrician to a patient with vascular parkinsonism. Dr. Michael Gordon ${ }^{(4)}$ reminisces about the personal life experiences that convinced him to become both a physician and a geriatrician. We are also happy to present the Proceedings of the Canadian Frailty Network Summit: Medication optimization for frail older Canadians, which took place in Toronto in April of this year. ${ }^{(5)}$

See you in 2018!

Dr. Kenneth M. Madden, Editor-in-Chief Colleen Maxwell, Associate Editor, Geriatric Medicine Mark Rapoport, Associate Editor, Geriatric Psychiatry Canadian Geriatrics Journal

\section{REFERENCES}

1. Byszewski A, Power B, Lee L, et al. Driving and dementia: workshop module on communicating cessation to drive. CGJ. 2017;20(4):241-45.

2. Loftus C. A., Wiesenfeld L. A. Geriatric delirium care: using chart audits to target improvement strategies. CGJ. 2017; 20(4):246-52.

3. Powell C. From physician to patient: a personal journey. CGJ. 2017;20(4):264-67.

4. Gordon M. The cauldron of life experiences that creates the geriatrician: a personal perspective. CGJ. 2017;20(4):268-69.

5. Muscedere J, Kim P, Aitken P, et al. Proceedings of the Canadian Frailty Network Summit: Medication optimization for frail older Canadians, Toronto, Monday April 24, 2017. CGJ. 2017; 20(4):253-63 